\title{
ACUTE PANCREATITIS COMPLICATED WITH COMBINED COPPER SULPHATE AND KEROSENE POISONING -A CASE REPORT
}

\author{
MD. ROBED AMIN, ${ }^{1}$ KANIZ FATEMA ANONNYA ${ }^{2}$, MD OMAR KHOSRU ${ }^{3}$, ABUL HAYAT MANIK ${ }^{4}$, RAQUIB \\ HASAN MOHAMMAD ${ }^{5}$
}

Received: 21 December 2014

Accepted: 3 March 2015

\section{Introduction:}

Copper sulphate pentahydrate (CSP) is a common and easily available substance used in agriculture as a fungicide, herbicide, algicide, mollluscide, fertilizer additive and also in steel and petroleum industry ${ }^{1}$. It is cheap and widely available in rural shop and devoid of significant pungent smell or bad taste. Farmer and fisherman use it for skin diseases. Reports of accidental or suicidal poisoning are rare in western countries, but are very common in India, accounting for more than $40 \%$ of all poisonings ${ }^{2}$. There has not been many publication on this particular poisoning but the southern part of Bangladesh is having many cases of such poisoning with huge mortality. Hospital based reports revealed the 25\% cases of fatality in Dhaka Medical College Hospital(DMCH) ${ }^{3}$ Copper inhibits enzymes, G 6 PD and glutathione reductas and therby rults in oxidizing injury to cell especially RBC, liver and kidney. Hemolysis is produced by the increased oxidation of hemoglobin sulfhydryl groups, leading to increased red blood cell permeability. Significant increases of copper content in the mitochondrion suggest hepatic mitochondrion to be an important target in hepatic toxicity, with an involvement of oxidant damage to the liver $1,2,4,5$. Intravascular haemolysis appears after 12-24h, Jaundice appears on the second or third day and Renal complications are usually seen on the third or the fourth day after ingestion of C.sulphate. GIToxicity is common in copper sulphate poisoning but toxicity leading to pancreatitis is uncommon ${ }^{5}$.

Kerosene is available in most homes where it is used as cooking fuel and for lighting. In household it is normally kept in bottles especially mineral water bottle, fruit and soda bottles. Poisoning with kerosene one of the commonest forms of acute childhood poisoning in many developing countries. In Dhaka Medical College Hospital 4-6\% of total admission in the pediatric department consists kerosene poisoning ${ }^{1}$. When ingested it is readily absorbed from the stomach and excreted by the lungs. Hydrocarbon may interact with pulmonary surfactant, resulting in alveolar collapse. Respiratory distress develops quickly and may be due to the ventilation perfusion abnormalities with resultant hypoxia. Although abdominal pain is common the severity leading to pancreatitis is a rarity in kerosene poisoning. Here is a case report which revealed both copper sulphate and kerosene poisoning by same individual and complicate with acute pancreatitis.

\section{Case Report:}

A 45 yrs female from Sonatan., Magura admitted in Dhaka Medical College Hospital (DMCH) on 15 the Jan 2013 with the history of suicidal attempt by intentional ingestion of Copper Sulphate (CuSO, ) \& Kerosene (hydrocarbon) simultaneously. Following household quarrel with her mother-in-law she intentionally ingested approximately 125-130 gm of powdered form of copper sulphate locally named as 'Tute' which was available in local market as herbicide or remedy of skin infection. She also took about 250 $\mathrm{ml}$ of hydrocarbon locally named as kerosene at the same time. Her daughter was the eye witness of this incident. Immediately after ingestion she started vomiting. The vomitus, contained food material having pungent odour of kerosene, projectile and voluminous. No history of blood or bile in vomitus. Patient also suffered from abdominal pain which was

1. Associate Professor of Medicine, Dhaka Medical College

2. Medical Officer, Dhaka Medical College Hospital

3. Assistant Registrar, Dhaka Medical College Hospital

4. Indoor Medical Officer, Dhaka Medical College Hospital

5. Registrar, Medicine department, Dhaka Medical College Hospital

Address of Correspondence: Dr.Md. Robed Amin, Associate Professor of Medicine, Department of Medicine, Dhaka Medical College, Bangladesh. E-mail: robedamin@yahoo.com

Bangladesh J Medicine 2015; 26 : 79-82 
severe, agonising, constant, burning in nature and extended throughout the chest, abdomen and throat. No history of diarrhoea rather patient gave history of relative constipation

Following 2-3 episodes of vomiting and continued abdominal pain patient became restless $\&$ distressed. Local doctors gave gastric lavage with water about $250 \mathrm{ml}$ and referred the patient to Magura Sadar Hospital. There all available emergency resuscitation including intravenous saline, oxygen and ionotropes was given and the patients general wellbeing was improved. But from $2^{\text {nd }}$ day of poisoning patient developed yellow discoloration of sclerae, urine $\&$ whole body. On enquiry she gave history of 2 episodes of black, tarry, semisolid, foul smelling stool that became red upon mixing water. On $3^{\text {rd }}$ day of poisoning patient experienced passage of bright red blood through urine. For progressive illness she was referred to Dhaka Medical College for better management. On admission to $\mathrm{DMCH}$ patient complaints of haematuria, intractable vomiting, jaundice, severe burning pain in upper abdomen, chest \& throat. Her jaundice disappeared on 10-11 days of poisoning. Haematuria improved on day 9 and disappeared on day 12 of poisoning. As patient was constipated she passed stool on $10^{\text {th }}$ day of poisoning $\&$ it was normal. On enquiry she gave history of occasional dry cough. No history of diurnal variation, no relation with posture, no aggravating or relieving factors.

On admission patient was ill looking, distressed, conscious. Her BP: 80/60, Pulse: $121 \mathrm{~b} / \mathrm{m}$, Temperature was $98^{\circ} \mathrm{F}$, Respiratory Rate was $18 \mathrm{~b} /$ min, She was found mild anemic and moderately dehydrated but rest of the general examination was unremarkable. On abdominal examination it was found scaphoid shaped, umbilicus was inverted, horizontal suprapubic incision. The abdomen was soft, diffusely tender mostly in epigastric region but no organomegaly or ascites. Her bed side urine was reddish and heat coagulation test was positive. Her systemic examination beside abdomen was unremarkable. Although she took kerosene at the same time, there was no respiratory findings during the observation period.

Her complete blood count revealed $\mathrm{Hb}$ was $10.7 \mathrm{gm} /$ dl, Total count of WBC was $24,530 / \mathrm{Cmm}$, with neutrophil $67.2 \%$, lymphocyte $25.9 \%$, monocyte $5.5 \%$, platelet count was 1,72,000 / Cmm, MCV: $82.1 \mathrm{fl}, \mathrm{MCH}$ : 27 pg, MCHC: 32.8 g/dl. Random blood sugar was $260 \mathrm{mg} / \mathrm{dl}$, S. Bilirubin was $4.9 \mathrm{mg} / \mathrm{dl}, \mathrm{S}$. Creatinine: $0.9 \mathrm{mg} / \mathrm{dl}$, SGPT: 186U/L Prothombin time was Control $13 \mathrm{sec}$ and patient 52sec. S. Electrolyte was $\mathrm{Na}-131.2 \mathrm{mmol} / \mathrm{l}, \mathrm{K}-5.6 \mathrm{mmol} / 1$ and Cl- 108.6 mmol/1. Peripheral blood film (15-01-13) described RBC: normochromia and normocytosis with frequent nucleated red cells, WBC Shows mild shift to the left with few myelocytes $\&$ otherwise normal maturation with adequate platelets. The Comment was Leucoerythroblastic blood picture

She was treated with a specific antidote with Inj Dimercaprol $250 \mathrm{mg} 6$ hourly for 4 days, 8 hourly for 2 days and 12 hourly for 5 days. Inj Methylene Blue was advised but it was not available at local market. She was also treated with supportive measures like nothing per oral, Infusion of normal Saline $2 \mathrm{~L}+$ $5 \%$ DNS $1 \mathrm{~L}$ per day, Inj Omeprazole 40mg 12 hourly, tab Sucralfate $2+2+2+2$ (30 min before meal), Inj Konakion 1 amp I/V daily for 3 days, Inj Ceftriaxone $1 \mathrm{gm} 12$ hourly for 10 days, Inj Dexamethasone 6 hrly for 3 days, 8 hrly for 2 days, 12 hourly for 5 days. On 16-01-13 her Serum. Lipase was 941 U/L, Serum. Amylase $351 \mathrm{U} / \mathrm{L}$. HBsAg and Anti HCV was Negative.On $20^{\text {th }}$ jan S. Creatinine $0.93 \mathrm{mg} / \mathrm{dl}$, S. Reticulocyte 08\%, S. Amylase 182 U/L and S. Lipase $57 \mathrm{U} / \mathrm{L} . \mathrm{On} 24^{\text {th }}$ jan $\mathrm{Hb}$ was $11.8 \mathrm{gm} / \mathrm{dl}$. ESR $13 \mathrm{~mm}$ in $1^{\text {st }}$ hour, Total count was $7,400 / \mathrm{cmm}$ with neurtrophil $78 \%$,lymphocyte $12 \%$,monocyte $02 \%$,eosinophil $01 \%$, S. Bilirubin was $0.90 \mathrm{mg} / \mathrm{dl}$ and SGPT $68 \mathrm{U} / \mathrm{L}$. The patient was discharged on $15^{\text {th }}$ day of poisoning after reviewing liver $\&$ renal function test. Patient was haemodynamically stable and during discharge she was treated with Cap Omeprazole(40 mg 12 hourly) for 14 days and tab Sucralfate $2+2+2+2$ for 14 days and tab Omidon (10mg) $1+1+1$ for 14 days. She was diagnosed as a case of copper sulphate and kerosene poisoning complicated with acute pancreatitis. She was on regular follow up with clinical and few biochemical tests. On 20-02-13 her Upper GIT Endoscopy was normal and repeat chest $\mathrm{x}$-ray PA view was also normal. Peripheral blood film dated 20-02-13 showed RBC normochromia and normocytosis, WBC was matured with adequate platelets and comment was mild normocytic anaemia

\section{Discussion}

Acute severe copper suplphate toxicity results in gastrointestinal injury with diarrhoea and melaena, haemolysis with haemoglobinuria and hemolytic anaemia, kidney and liver failure, and even shock syndrome with profound hypotension, coma and lethal outcome. Early deaths are the consequence of shock, while late mortality is related to renal and hepatic failure ${ }^{6}$. The combined clinical features are common as consequence and it has been observed in our case also. Although the kidney involvement was not observed in this case, the GI toxicity and followed by 
hepatic toxicity was the classical presentation of combined features. The patient developed anemia due to intravascular haemolysis and peripheral blood film (PBF) also showed nucleated RBC and premature cell accumulation leading to acomment of leucoerythroblastic blood picture. After recovery, the PBF was completely normal and excluding any other infiltrative bone marrow diseases. There was a mild drop in haemoglobin level which would have been contributed by the copper induced haemolysis (increased total bilirubin and indirect bilirubin fraction, evidence from blood picture, increased reticulocyte index). The methaemoglobinaemia could not be confirmed by biochemically as the assay was unavailable at the hospital.

Her abdominal pain and clinical features resembled acute pancreatitis (epigastric pain radiating to back, lack of hard abdominal signs despite severe pain) and interestingly the serum amylase level and lipase was also very high. She was treated as for acute pancreatitis and the serum amylase level returned to baseline as the overall condition improved. There was huge leucocytosis which can be due to acute pancreatitis or concomitant sepsis. This was also observed in other studies of severe copper sulphate poisoning ${ }^{7,8}$. The leucocytosis and Haemoglobin at follow up become normal indicating recovery from sepsis.

Acute liver failure, and/or icterus, and/or hepatomegaly, and/or increased serum transaminases, and/or prolongation of prothrombin time are among signs of the hepatotoxic Copper Sulphate Poisoning effect ${ }^{2,6,9}$. This was observed in the index case indicating the liver involvement as a common manifestation. In our case, the remarkable feature was absence of renal involvement. The haemoglobinuria and dehydration was managed with meticulous process and thereby probably prevents the renal damage.

An important feature of this patient was paucity of features of kerosene poisoning although there was hydrocarbon smell in her breath since admission. There was no respiratory distress and chest xray was unremarkable. There was no fever and hopoxic encephalopathy was absent which indicate mild kerosene poisoning effect. The pancreatitis that developed is also unlikely to be due to kerosene poisoning as hydrocarbon leads to diarrhea more rather toxic effect on pancreas.

Chelation therapy in copper sulphate poisoning aims at removing ingested copper from the body. The efficacy of these chelating agents is unproven. Penicillamine is a commonly used chelating agent at a dose of $1-1.5 \mathrm{~g} / \mathrm{d}$ in $2-4$ divided doses ${ }^{5}$. But our patients had severe abdominal pain with repeated vomiting which lead us to start chelation with inj Dimercaprol. Intramuscular administration of dimercaprol or British anti-Lewisite (BAL) (3-5 mg/ $\mathrm{kg} /$ dose with four hourly administration in first two days and tailed off over a total of 7-11 days) is recommended when oral administration of penicillamine is difficult or contraindicated. Our patient responded very well with the regime with complete recovery. The pancreatitis sequalae was absent and within two weeks all the features of pancreatitis resolved. The patient received inj Ceftriaxone for 10 days as prophylaxis for pancreatitis and sepsis. The patient also received Inj Dexamethasosne for haemolysis as there has been reports that it reduced haemolytic process in presence of haemoglobinuria ${ }^{1,2,10}$.

The outcome of the patient was complete recovery with only local (Gluteal abscess) due to inj Demarcaprol use. The abscess healed completely by using antibiotics and patient was discharged with follow up. Two weeks later the patient was seen in complete physical and psychological recovery with regular counseling by psychiatrist in outdoor.

\section{Conclusion}

Despite being rare, intoxication with copper sulphate can be fatal. The effects of poisoning can have deleterious effects on the upper digestive tract, kidneys, liver and blood (intravascular haemolysis, methaemoglobinaemia). We have observed that our patients had typical clinical features of acute pancreatitis (not a recognized complication) with an elevated serum amylase and lipase level. We recommend that physicians treating such patients assess the serum amylase and lipase level during the acute illness. We also recommend to concentrate on prevention of copper sulphate ingestion by measures such as stopping over the counter sale of copper sulphate and restriction of purchase, distribution and sale to authorized agents only.

\section{Consent}

Written informed consent was obtained from the patient for publication of this case report.

\section{List of abbreviations}

Abbreviations are explained where they are first used in text

\section{Competing interests}

The authors declare that they have no competing interests. 


\section{References}

1. Md. Abul Faiz, Md. Mizanul Hoque, Shakil Ahmed, Md. Robed Amin, Aniruddha Ghose. Training manual of Poisoning (National Guideline of poisoning-2008). World Health Organization (WHO), Environmental Health Unit, Dhaka, Bangladesh. ISBN: 984300000626

2. Agarwal BN, Bray SH, Bercz P, Plotzker R, Labovitz E. Ineffectiveness of hemodialysis in copper sulphate poisoning. Nephron 1975;15:74-7.

3. Khan Abul Kalam Azad et al. Year book of Department of Medicine, 2011.

4. Pandit AN, Bhave SA. Copper metabolic defects and liver disease: Environmental aspects. J Gastroenterol Hepatol 2002;17(Suppl 3):S403-7.

5. Saravu K, Jose J, Bhat MN, Jimmy B, Shastry B. Acute ingestion of copper sulphate: A review on its clinical manifestations and management. Indian $\mathrm{J}$ Crit Care Med. 2007;11:74-80. doi: 10.4103/09725229.33389
6. Oldenquist G, Salem M. Parenteral copper sulfatepoisoning causing acute renal failure. Nephrol DialTransplant 1999;14:441-3.

7. Gunay N, Yildirim C, Karcioglu O, Gunay NE, Yilmaz M, Usalan C, Kose A, Togun I. A series of patients in the emergency department diagnosed with copper poisoning: recognition equals treatment. Tohoku J Exp Med. 2006;209:243-248. doi: $10.1620 /$ tjem.209.243

8. Sinkovi A, et al. Severe acute Copper Sulphate Poisoning: A Case report. Arh Hig Rada Toksikol 2008;59:31-35

9. Oon S, Yap CH, Ihle BU. Acute copper toxicity following copper glycinate injection. Intern Med J 2006;36:741-3.

10. Franchitto N, Gandia-Mailly P, Georges B, Galinier A, Telmon N, Ducasse JL, Rouge D. Acute copper sulphate poisoning: a case report and literature review. Resuscitation. 2008;78:92-96. doi: 10.1016/j.resuscitation. 2008.02.017. 